\title{
Diagnostic characters of the larvae of some Hoplothrips species (Thysanoptera: Tubulifera) in Norway
}

\author{
SVERRE KOBRO and Trond RAFOSS \\ The Norwegian Crop Research Institute, Plant Protection Centre, Høgskoleveien 7, N-1432 Ås, Norway; e-mail: \\ sverre.kobro@planteforsk.no
}

Key words. Thysanoptera, Hoplothrips, larvae, identification, mathematical approach.

\begin{abstract}
Characteristics of 46 setae of the second stage larvae of four Hoplothrips species (Thysanoptera) are discussed with respect to their diagnostic value. Two different approaches, of which one is mathematical, for identification of the larvae are given.
\end{abstract}

\section{INTODUCTION}

Thrips are among the smallest insects, as most of them are 1-2 mm long. Additionally many species live in hidden habitats and are difficult to study. Hence information about them is limited.

The development of thrips differs from that of other insects by having two larval stages and two or three pupal stages. The larvae of many thrips species are poorly known or undescribed. Priesner (1928) gave very detailed descriptions of the larvae of many species, but the characters he used are difficult to emply for identification. Some identification keys are available, but focus on species of economic interest within the suborder Terebrantia (Speyer \& Parr, 1941; Miyasaki \& Kudo, 1986; Nakahara \& Vierbergen, 1998). Although the suborder Tubulifera contains the largest number of species, few descriptions of their larvae that are useful for identification are available. Heming (1991) gave some examples, and Priesner (1964), an identification key to a number of second stage larvae of the Tubulifera, but this is far from complete.

The larvae of many insects can be identified prior to complete development, but the best way to verify identification of larvae is often to let them complete their development and identify the imagines. Details of importance for identification of thrips larvae can be studied only after elaborate preparation of preserved specimens. Accordingly the next best way to verify identification of them may be to collect them from populations containing both larvae and imagines, to identify the imagines, and to assume that the larvae and the imagines belong to the same species.

Several Hoplothrips species (Tubulifera) have been collected in Norway. According to Priesner (1964) and Ananthakrishnan (1984) the species live gregariously on wood-rotting fungi. They live on recently dead and fungal infested trees often with large numbers of imagines and larvae together.

The Hoplothrips studied here were collected from populations containing a single species of imagines, and therefore all the larvae were assumed to belong to the same species. In this context all specimens on a single tree were regarded as belonging to one population as most of the imagines were wingless (Lewis, 1973; Kobro, 2001) and thus reproductively isolated. They probably developed from one single or a very few primary invaders of the dead tree.

Hoplothrips polysticti (Morison, 1949) is probably monophagous on Trichaptum abietinum (Kobro, 2001), which is a very common wood-rotting polypore on Picea abies (Ryvarden \& Gilbertson, 1994). Hoplothrips pedicularius (Haliday, 1836) forage on the bark fungi Stereum spp. (Morison, 1949; Priesner, 1964) infesting many different species of trees (Eriksson et al., 1984). Hoplothrips carpathicus Pelikán, 1961 was earlier recorded from dead Fagus silvatica (Pelikán, 1961; zur Strassen, 1994) but without information on any fungal infestation of the tree. zur Strassen (1994) described it as a "hardly known" species, and gave a description of the larva based on one specimen. H. carpathicus was later found in numbers on standing dead birches with coarse and cracked bark in Sweden (Kobro \& Nittérus, 1999) and Norway. The birches were infested by Fomes fomentarius. According to Morison (1949) Hoplothrips ulmi (Fabricius, 1781) occurs on Peniophora incarnata and other fungi. $P$. incarnata infests most sorts of wood (Eriksson \& et al., 1978). Thus the species probably forage on different fungi and therefor they are usually not found together.

The larvae of four of the most commonly found Hoplothrips species in Norway are described using the chaetotaxy that are of importance for identification. Two different approaches to identification keys are given: one traditional key based on a combination of judgement of qualitative and quantitative traits, and one using a strictly quantitative, mathematical approach.

Three other species of the same genus were found during this investigation. Hoplothrips corticis (De Geer, 1773) was found once with one second stage larva. Single adult individuals of Hoplothrips fungi (Zetterstedt, 1828) and Hoplothrips unicolor (Vuillet, 1914) were found.

Additionally Hoplothrips semicaecus (Uzel, 1895) has been recorded once in Norway (Olsen \& Solem, 1982). 


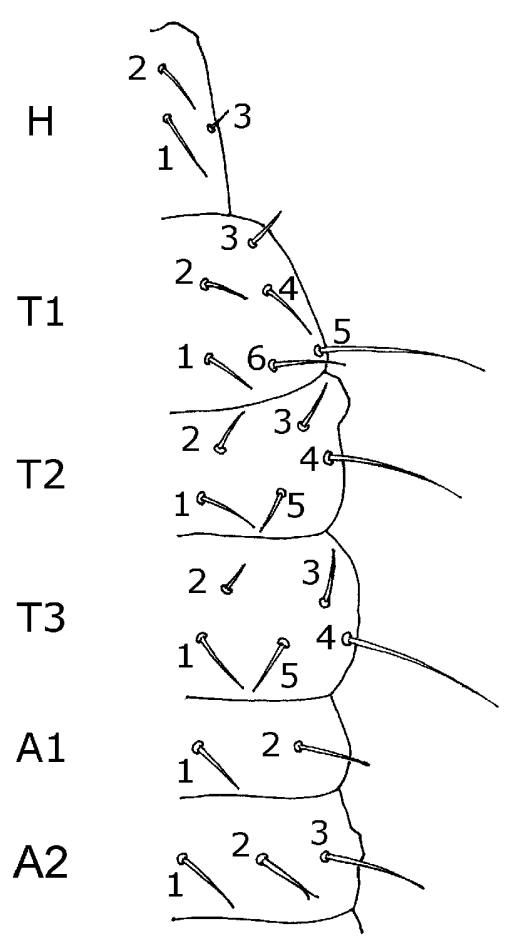

Fig. 1. Setal map of the second stage larva of Tubulifera, redrawn after Heming (1991).

\section{MATERIALS AND METHODS}

Bark was collected from 1998 to 2000 from several species of dead trees with visible infections of wood-rotting fungi. The sample size was about $0.2-0.3 \mathrm{~m}^{2}$. Thrips were eluated from Berlese funnels and stored in AGA $(70 \%$ ethanol + glycerol + acetic acid $=10+1+1$ ). The number of specimens eluated from one sample varied from zero to more than a hundred. The larvae studied in this investigation were selected preferentially from samples with a high number of larvae and imagines, and containing imagines of only a single species of Hoplothrips. Imagines were identified following Priesner (1964) and Schliephake \& Klimt (1979). Identification of representatives of the species were verified by R. zur Strassen (pers. com.).

Five second stage larvae from each of three populations of $H$. polysticti, $H$. pedicularius and $H$. carpathicus were studied, but only two populations of $H$. ulmi were found so the number of specimens was less.

After storage, the larvae were treated with $50 \%$ hot lactic acid (lactic acid $+96 \%$ ethanol $=1+1$ ) for 15 minutes and concentrated acetic acid for a few minutes and, thereafter, in $50 \%$ clove oil (clove oil $+100 \%$ ethanol $=1+1$ ) overnight. After $5-10$ minutes in pure clove oil they were embedded in Canada balsam.

TABLE 1. Estimated coefficients of linear discrimination functions for classification of second stage larvae of four Hoplothrips species.

\begin{tabular}{lrrrrc}
\hline & seta & seta & seta & seta & constant \\
& A9.2 & T1.1 & H1 & A8.2 & value \\
\hline *H. carpathicus & 0.41 & 0.23 & 0.66 & 0.42 & -57.94 \\
H. pedicularius & 0.91 & 0.03 & 0.84 & 0.37 & -101.13 \\
H. polysticti & 1.37 & -0.11 & 0.72 & 0.27 & -145.11 \\
H. ulmi & 1.47 & 0.18 & 0.88 & 0.40 & -205.64 \\
\hline
\end{tabular}

*Example: $f_{\text {H. carpathicus }}=$ seta A9.2 $\times 0.41+$ seta $\mathrm{T} 1.1 \times 0.23+$ seta $\mathrm{H} 1 \times 0.66+$ seta $\mathrm{A} 8.2 \times 0.42-57.94$

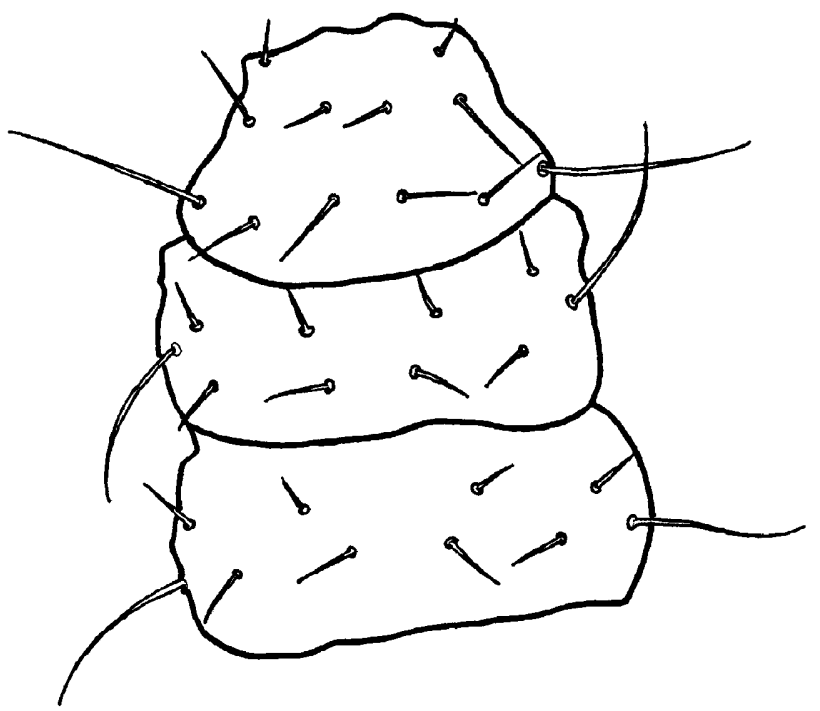

Fig. 2. Setal map of the thorax of the second stage larva of Hoplothrips polysticti.

The setae of the larvae were numbered following Heming (1991) (Fig 1). The length of 46 setae on each of the 53 specimens was measured and the setae were also characterised regarding the shape of their apex.

The length of each seta was measured using a microscope with 500 times magnification. As the setae on prepared specimens usually are not lying in the focal plane, both the horizontal projection and the vertical component of the length were measured, and the true length was calculated as the hypotenuse (Cederholm, 1981). The horizontal projection of a setae length was read with an ocular micrometer (calibrated using a Leitz standard slide). To measure the vertical component of the setae length, the scale of the focusing screw on the microscope was used. A calibration factor was established by means of a slide specially made for the purpose by $\mathrm{T}$. Krekling: he made a cross with ink on a cover glass, with one line on each side of the glass. The true thickness of the cover glass was measured with a micrometer. The same thickness, that is the distance between the two crossing lines, could then be measured on the microscope, and the calibration factor could be calculated.

The lengths of the setae were compared using a one-way ANOVA and multiple comparisons using the Fisher LSD test.

A mathematical approach to identification of insects may be based on multivariate mathematical statistics. Such techniques have been applied previously by Mound \& Palmer (1981) for the classification of thrips species by clustering specimens based on morphological traits. They used principal component and canonical variate analysis, but with limited success. For our purpose, the discrimination of species based on quantitative measures of the setae, we used linear discriminant analysis (Johnson \& Wichern, 1992) as the appropriate statistical method. In linear discriminant analysis, we estimated one discriminant function based on a limited number of measured traits for each species (Table 1). When measurements on a new specimen are put into each one of these functions, the specimen is predicted to belong to the species for which the function gives the largest output value. We used this method for classification of our collected material.

\section{RESULTS}

Of the 46 setae measured, 20 were useful to distinguish among the four species $H$. carpathicus, H. pedicularius, 
TABLE 2. Mean setal lengths in $\mu \mathrm{m}$ (St dev) discriminating the second stage larvae of four Hoplothrips species.

\begin{tabular}{|c|c|c|c|c|c|c|c|c|}
\hline \multicolumn{9}{|c|}{ Hoplothrips } \\
\hline \multirow{2}{*}{$\begin{array}{l}\text { Seta } \\
\text { H.1 }\end{array}$} & \multicolumn{2}{|c|}{$\begin{array}{l}\text { carpathius } \\
\mathrm{n}=15\end{array}$} & \multicolumn{2}{|c|}{$\begin{array}{c}\text { pedicularius } \\
\mathrm{n}=15\end{array}$} & \multicolumn{2}{|c|}{$\begin{array}{l}\text { polysticti } \\
\mathrm{n}=15\end{array}$} & \multicolumn{2}{|r|}{$\begin{array}{l}\text { ulmi } \\
\mathrm{n}=8\end{array}$} \\
\hline & 59 & $(7)^{* *}$ & 67 & $(7)^{* * *}$ & 60 & $(7)^{* *}$ & 83 & $(6)^{* * *}$ \\
\hline H.2 & 25 & $(4)^{*}$ & 34 & $(7)^{*}$ & 26 & 6 & 38 & 3 \\
\hline T1.1 & 59 & $(8)^{*}$ & 62 & $(10)^{*}$ & 58 & $(9)^{*}$ & 93 & $(13)^{* * *}$ \\
\hline $\mathrm{T} 1.6$ & 76 & $(6)^{* * *}$ & 60 & $(9)^{*}$ & 64 & $(10)^{*}$ & 62 & $(7)^{*}$ \\
\hline $\mathrm{T} 2.2$ & 24 & $(2)^{* * *}$ & 39 & $(5)^{* *}$ & 32 & $(5)^{* *}$ & 36 & $(6)^{*}$ \\
\hline $\mathrm{T} 2.3$ & 49 & $(6)^{* * *}$ & 39 & $(4)^{* *}$ & 32 & $(5)^{* * * *}$ & 39 & $(8)^{* *}$ \\
\hline $\mathrm{T} 2.4$ & 178 & $(20)^{* *}$ & 136 & $(17)^{* *}$ & 142 & $(14)^{* *}$ & 164 & $(9)^{* *}$ \\
\hline $\mathrm{T} 2.5$ & 52 & $(5)^{* * *}$ & 44 & $(7)^{*}$ & 46 & $(7)^{* *}$ & 39 & $(3)^{* *}$ \\
\hline T3.2 & 22 & $(4)^{* * *}$ & 37 & $(4)^{* *}$ & 31 & $(6)^{* * *}$ & 36 & $(4)^{* *}$ \\
\hline T3.3 & 46 & $(6)^{*}$ & 49 & $(7)^{*}$ & 37 & $(3)^{* * *}$ & 47 & $(5)^{*}$ \\
\hline T3.4 & 195 & $(22)^{* *}$ & 154 & $(14)^{* *}$ & 157 & $(15)^{* *}$ & 181 & $(10)^{* *}$ \\
\hline T3.5 & 54 & $(5)^{* * * *}$ & 43 & $(5)^{*}$ & 43 & $(7)^{*}$ & 40 & $(2)^{*}$ \\
\hline A 1.2 & 84 & $(14)^{* * *}$ & 53 & $(10)^{*}$ & 50 & $(8)^{*}$ & 53 & $(8)^{*}$ \\
\hline A5.3 & 130 & $(18)^{* * *}$ & 159 & $(21)^{*}$ & 150 & $(13)^{*}$ & 156 & $(21)^{*}$ \\
\hline A6.1 & 86 & $(13)^{* * *}$ & 74 & $(9)^{*}$ & 73 & $(11)^{*}$ & 72 & $(5)^{*}$ \\
\hline A7.1 & 101 & $(16)^{* * *}$ & 73 & $(10)^{*}$ & 84 & $(21)^{*}$ & 72 & $(9)^{*}$ \\
\hline A8.1 & 98 & $(21)^{* * *}$ & 67 & $(7)^{*}$ & 68 & $(19)^{*}$ & 77 & $(8)^{*}$ \\
\hline A 8.2 & 88 & $(15)^{*}$ & 84 & $(12)^{*}$ & 62 & $(10)^{* * *}$ & 90 & $(14)^{*}$ \\
\hline A9.2 & 66 & $(6)^{* * * *}$ & 123 & $(15)^{* * *}$ & 173 & $(11)^{* * * *}$ & 195 & $(9)^{* * *}$ \\
\hline A9.3 & 139 & $(26)^{* * *}$ & 169 & $(17)^{* *}$ & 189 & $(12)^{* *}$ & 185 & $(13)^{*}$ \\
\hline
\end{tabular}

*** Mean is significantly different from the three other species

** Mean is significantly different from two of other species

* Mean is significantly different from one of other species $(\mathbf{P}<0.01)$

$H$. polysticti and $H . \quad u l m i$, as their means were significantly different from at least one of the other species (Table 2). Most setae on the one second stage larva of $H$. corticis were strikingly longer (not shown).

The setae were also characterised regarding the form of their apex. For $H$. carpathicus and $H$. corticis all the setae were sharply pointed. For $H$. polysticti all setae on the head, pronotum and mesonotum were sharply pointed (Fig 2), while the shorter setae on the metanotum and abdomen were more variable, beeing fringed (see A2.2 in Fig.1), blunt or pointed. In contrast, the fringed setae were dominant on $H$. pedicularius and $H$. ulmi, despite some variation in the form of the apices of the setae.

TABLE 3. Identification key I for the second stage larvae of four species of Hoplothrips.

\begin{tabular}{|c|c|}
\hline 1 Several setae on pronotum fringed & 2 \\
\hline All setae on pronotum sharply pointed & 3 \\
\hline 2 Setae A9.1-3 about the same length: & Hoplothrips ulmi \\
\hline Seta A9.2 much shorter: & $\begin{array}{l}\text { Hoplothrips pedicu- } \\
\text { larius }\end{array}$ \\
\hline $\begin{array}{l}3 \text { Seta pair } \mathrm{T} 1.2 \text { on, or close to the line } \\
\text { between seta pair } \mathrm{T} 1.3\end{array}$ & $\begin{array}{l}\text { Hoplothrips carpa- } \\
\text { thicus }\end{array}$ \\
\hline $\begin{array}{l}\text { Seta pair } \mathrm{T} 1.2 \text { on, or close to the line } \\
\text { between seta pair } \mathrm{T} 1.4\end{array}$ & $\begin{array}{l}\text { Hoplothrips polys- } \\
\text { ticti }\end{array}$ \\
\hline
\end{tabular}

TABLE 4. Identification key II for the second stage larvae of four species of Hoplothrips.

\begin{tabular}{ccc}
\hline 1 Length of seta A9.2 & $66(6) \mu \mathrm{m}$ & Hoplothrips carpathicus \\
“" & $123(15) \mu \mathrm{m}$ & Hoplothrips pedicularius \\
“" & $173(11) \mu \mathrm{m}$ & Hoplothrips polysticti \\
" & $195(13) \mu \mathrm{m}$ & Hoplothrips ulmi \\
\hline
\end{tabular}

The classification of thrips species based on linear discriminant analysis identified four setae to be sufficient for correct classification. Estimated factors for the discriminant functions for these four setae are given in Table 1.

\section{DISCUSSION}

In his identification key Priesner (1964) used, among other characters, the shape of the apex of the setae, and also the relative length of setae 1,2 and 3 on the 9th abdominal segment (= A9.1, A9.2 and A9.3), for identification of Hoplothrips species. Based on these, and one additional character more or less subjectively chosen by us, an identification key for larvae of four Hoplothrips species was made in the traditional way, including the two species, $H$. carpathicus and $H$. polysticti, not noted by Priesner (1964) (Table 3).

The mathematical treatment of our data increased the diagnostic value of several of the setae and, thereby, simplified the identification of the four species studied. Their seta lengths alone could identify the species. The estimated linear discriminant functions (Table 1), classified all observations to their correct species. The seta A9.2 was clearly the best single classification variable (lowest pooled standard deviation), but, for a further refinement and especially to distinguish the species $H$. ulmi from $H$. pedicularius and $H$. polysticti, we had to include the three setae T1.1, H1 and A8.2. Checking off the discriminant model by cross-validation, misclassified only one specimen ( $H$. pedicularius to $H$. carpathicus) of a total of 53 specimens.

The two different identification approaches resulted in two different keys, of which one is based on one character only (Table 4).

In addition to the metric characters discussed, the larvae of some of these Hoplothrips species can be discriminated by the colour of fresh specimens. H. ulmi have an orange coloured pigmentation within the body, whereas $H$. carpathicus is grey with a more or less orange coloration only in the middle of abdomen (Kobro \& Nittérus, 1999; photo). The three other species discussed here are crimson.

\section{CONCLUSION}

By including a mathematical treatment, the diagnostic value of metric characters can be increased, thereby reducing the number of characters needed for correct identification of the larvae of the four Hoplothrips species studied.

ACKNOWLEDGEMENTS. We thank Gry Alfredsen for her help in identifying the fungi. 


\section{REFERENCES}

ANANTHAKRISHNAN T.N. 1984: Bioecology of Thrips. Indira publishing house. Oak Park, Michigan, USA, 229 pp.

Cederholm L. 1981: Variation in Thrips angusticeps f. macroptera Uzel, with lectotype designations (Thysanoptera: Thripidae). Ent. Scand. Suppl. 15: 237-250.

CRESPI B.J. 1986: Territoriality and fighting in a colonial thrips, Hoplothrips pedicularius, and sexual dimorphism in Thysanoptera. Ecol. Entomol. 11: 119-130.

Eriksson J., Huortstam K. \& Rrvarden L. 1978: The Corticiaceae of North Europe. Fungiflora- Oslo-Norway 5: 927-928.

ERIKSSON J., HJoRtstam K. \& Ryvarden L. 1984: The Corticiaceae of North Europe. Fungiflora- Oslo-Norway 7: 1416-1435.

Heming B.S. 1991: Order Thysanoptera. In Stehr F.W. (ed.): Immature Insects 2: 1-21.

JoHnson R. \& WICHERn D. 1992: Applied Multivariate Statistical Methods. Third Edition, Prentice Hall, 493 pp.

LeWIs L. 1973: Thrips. Their Biology, Ecology and Economic Importance. Academic Press, London and New York, 349 pp.

KoвRo S. 2001: Hoplothrips polysticti (Thysanoptera) living on Picea abies infested by Trichaptum abietinum. Entomol. Fennica 12: 15-21.

Kobro S. \& NitTÉRus K. 1999: Tripsar i döda björkar. [Thrips in dead birches.] Ent. Tidskr. 120: 93-98 (in Swedish, English abstr.).

Mryasaki M. \& Kudo I. 1986: Description of thrips larvae which are noteworthy on cultivated plants (Thysanoptera: Thripidae). I. Species occurring on solanaceous and of cucurbitaceous crops. Akitu. New Series 79: 1-26.

Morison G.D. 1949: Thysanoptera of the London area. Part III. Key to the British genera and species of Thysanoptera (cont.).
The London Naturalist. The Journal of the London Natural History Society 28: 77-131.

Mound L.A. \& Palmer J.M. 1981: Phylogenetic relationships between some genera of Thripidae (Thysanoptera). Ent. Scand. Suppl. 15: 153-170.

NAKahaRa S. \& Vierbergen G. 1998: Second instar larvae of Frankliniella species in Europe (Thysanoptera: Thripidae). Proceedings, 6th International Symposium on Thysanoptera. Akdeniz University, Antalya, Turkey, pp. 113-120.

OLsen A. \& SOLEM J.O. 1982: On the Norwegian thrips fauna (Thysanoptera). Fauna Norv. Ser. B 29: 5-16.

PeliKán J. 1961: New species of Thysanoptera from Czechoslovakia IV. Acta Soc. Entomol. Cechosloveniae 1: 60-70.

Priesner H. 1928: Die Thysanopteren Europas. Verlag von Fritz Wagner, Wien, $755 \mathrm{pp}$.

Priesner H. 1964: Ordmung Thysanoptera. Akademie-Verlag, Berlin, 242 pp.

Ryvarden L. \& Gilbertson R.L. 1994: European Polypores. 2. Synopsis fungorum 7. Fungiflora-Oslo-Norway, pp. 675-679.

Schliephake G. \& Klimt K. 1979: Thysanoptera, Fransenflügler. Die Tierwelt Deutschlands, 66. VEB Gustav Fisher Verlag, Jena, $475 \mathrm{pp}$.

SPEYER E.R. \& PARR W.J. 1941: The external structure of some Thysanopterous larvae. Trans. R. Ent. Soc. Lond. 11: 559-635.

STRASSEN ZUR R. 1994: On some rare fungivorous phlaeothripid Thysanoptera (Insecta) from Germany and Sweden. Strassen, R. z. (ed.): Proceedings of the Workshop on Thysanoptera at Bejing, China, and of the Symposium on Thysanoptera at Halle, Germany, both in 1992. Courier Forschungsinstitut Senckenberg 178. Senckenbergischen Gesellschaft. Frankfurt am Main, Germany, pp. 115-119.

Received March 3, 2001; revised June 30, 2001; accepted September 3, 2001 